\title{
Optimization of Process Parameters for Minimum Out- of-Roundness of Cylindrical Grinding of Heat Treated AISI 4140 Steel
}

\author{
Taranvir Singh, Parlad Kumar, Khushdeep Goyal* \\ Department of Mechanical Engineering, Punjabi University, Patiala, India \\ *Corresponding author: khushgoyal@yahoo.com \\ Received February 09, 2014; Revised February 18, 2014; Accepted March 10, 2014
}

\begin{abstract}
In this present work, the effect of input parameters viz. grinding wheel speed, work-piece speed, abrasive grain size, depth of cut, concentration of cutting fluid, and number of passes has been found on the out-ofroundness of cylindrical grinded AISI 4140 steel. Out-of-roundness is of great importance in case of shafts, axles, pistons, piston pins, crankshafts, roller bearings as out of roundness in these components can lead to excessive noise, vibrations, component failure, etc. so there is need to optimize the input parameters to have minimum out of roundness error. Three levels of each variable have been selected except wheel speed. Two levels of wheel speed have been taken. Heat treated AISI 4140 steel is selected as the work-piece material. The experiment is designed by using Taguchi's L18 orthogonal array. The effect of all the input parameters on the output responses have been analyzed using analysis of variance (ANOVA). The result reveals that abrasive grain size is the most significant to influence out-of-roundness, followed by work speed and number of passes. The optimum set of input parameters for minimizing the out-of-roundness has also been found.
\end{abstract}

Keywords: input parameters, cylindrical grinding, out-of-roundness, ANOVA, Taguchi

Cite This Article: Taranvir Singh, Parlad Kumar, and Khushdeep Goyal, "Optimization of Process Parameters for Minimum Out-of-Roundness of Cylindrical Grinding of Heat Treated AISI 4140 Steel.” American Journal of Mechanical Engineering, vol. 2, no. 2 (2014): 34-40. doi: 10.12691/ajme-2-2-1.

\section{Introduction}

In cylindrical grinding out-of-roundness is of great importance in case of shafts, axles, pistons, piston pins, crankshafts, roller bearings as out of roundness in these components can lead to excessive noise, vibrations, component failure, etc. so there is need to optimize the input parameters to have minimum out of roundness error. In the present study experiments are conducted to find optimum value of input parameters for minimum out of roundness. The input parameters selected are grinding wheel speed, work-piece speed, abrasive grain size, depth of cut, concentration of cutting fluid, and number of passes. In present the study, heat treated AISI 4140 steel has been selected as the test material because in industry, there are a number of applications of this material and it is generally used for manufacturing of bearings, bushes, gears, conveyor rolls and shafts. Taguchi's L18 orthogonal array is used to design the experiment and the effect of input parameters on out of roundness has been studied by using analysis of variance (ANOVA).

\section{Literature Survey}

Xue et al. [1] studied the monitoring of wheel dressing operations for precision grinding. Acoustic emission sensor attached with the dresser holder was used to monitor the dressing of the grinding wheel. The study was aimed on detection of out-of-round wheel, wheel contour errors and to improve the quality of ground work piece by monitoring the dressing parameters. The authors concluded that the dressing had affected the surface roughness more than that affected by depth of cut and table speed. Further, the monitoring of the dressing parameters resulted in better repeatability of surface finish in consequent grinding operations. Chidambaram et al. [2] formed a mathematical model for grinding marks in fine grinding of silicon wafers. The experiments were conducted on a Strasbaugh model 7AF wafer grinder and de-ionized water was used as coolant. The authors found that with the increase in chuck speed, the distance between adjacent grinding lines was increased while the line distance was decreased with the increase in grinding wheel speed. The authors further concluded that with the increase in speed ratio the line distance was increased and the grinding lines tend to become less curved. Krajnik et al. [3] used response surface methodology for design of grinding factors. The authors performed the experiments on a centre less grinding machine tool with vitrified grinding wheel (22A60L6V63L) with an abrasive blend of special mono crystalline and white aluminum oxide. The input parameters selected were the component centre height (h), the longitudinal dressing and in-feed speed. The surface roughness was taken as output parameter. 
From analysis of variance the authors found that the effect of grinding wheel dressing condition on surface roughness is most significant. The surface roughness was also affected by geometrical grinding gap set up factors and control wheel speed but this was not valid for the conventional centre less grinding at $30 \mathrm{~m} / \mathrm{s}$, where only the dressing factors predominate. Kwak [4] applied Taguchi's response surface methodologies for geometric error in surface grinding process. The grinding parameters selected were wheel speed, table speed, depth of cut and grain size while geometric error was the output parameter. The author concluded that the depth of cut affected the geometric error more than grain size while the wheel speed and table speed had lower effects. Minimum geometric error was obtained at the wheel speed of 1800 rpm, table speed of $10 \mathrm{~m} / \mathrm{min}$, depth of cut of $10 \mu \mathrm{m}$ and 46 mesh grain. On the basis of observed data a response surface model for the geometric error was developed.

Marsh et al. [5] carried out in process measurement of form error and force in cylindrical plunge grinding. Twospindle arrangement was used for experimental verification. The four capacitive probes embedded in the work spindle provided an estimate of grinding force by measuring the time varying gap between the spindle rotor and stator. A single probe was used to monitor the work piece size. Annealed 416 stainless steel was used as a work piece. The experiments were carried out at grinding wheel speed of $3600 \mathrm{rpm}$ and work piece speed of 330 rpm. The authors found that the grinding force was zero prior to contact of the abrasive wheel with the work piece and as the wheel approached the work piece the grinding force began to increase. The grinding force was increased to approximately $8 \mathrm{~N}$, while the material removal rate is less than the expected value due to the structural stiffness of the grinding machine. The authors further concluded that the roundness was improved during spark out stage.

Agarwal et al. [6] worked on modeling and prediction of surface roughness in ceramic grinding. The authors developed an analytical model based on the analysis of un-deformed chip thickness and the grooves left by the grinding wheel grains on the surface of ceramic work piece for the prediction of surface roughness of ground ceramics. The model also incorporated the overlapping effect of grooves left by grains which made the model more realistic. The model was compared with the existing models and it was concluded that surface roughness was increased with the increase in feed and depth of cut. Further, the increase in depth of cut increased the maximum chip thickness which resulted in poor surface quality. Kadirgama et al. [7] used surrogate modeling for predicting surface roughness and texture of surface when grinding AISI-1042 carbon steel. The authors conducted the experiments on Okumoto CNC surface grinder with medium grade alumina wheel having grain size number of 60. The authors used perthometer to measure surface roughness. The measurements were taken in directions parallel and perpendicular to the grinding direction. The average of these measurements was taken as roughness of ground surface. Three factors were selected for study namely work speed (rpm), diameter of work-piece (mm), depth of cut $(\mu \mathrm{m})$ and three levels of each of them were used. The Box-Behnken Design was used for design of experiment. The authors concluded that the optimum cutting parameters for minimum surface roughness were cutting speed $120 \mathrm{rpm}$, depth of cut $20 \mu \mathrm{m}$ and diameter $18 \mathrm{~mm}$. The error in surface roughness obtained by minimum surface roughness model or response surface model was $2.15 \%$. In case of surface texture, the steel specimens show surface fracturing and plastic flow under low speed conditions, it was due to high temperatures developed in low speed grinding. This behavior was also observed at medium speed, however improved the surface condition to some extent by carrying away certain amount of heat.

Kumar et al. [8] aimed at finding the optimal material removal and effect of process parameters of cylindrical grinding machine by Taguchi method. Depth of cut and cutting speed were selected as input parameters and material removal rate (MRR) was selected as response parameter. The experiment was designed using L-9 orthogonal array with three levels of each input variables. Analysis of variance (ANOVA) was used to investigate the effect of parameters which revealed that the influence of the cutting speed was significantly more than depth of cut. The authors found that the optimum MRR was 19.906 $\mathrm{mm}^{3} / \mathrm{s}$ with cutting speed of $41.07 \mathrm{~m} / \mathrm{min}$ and depth of cut $0.020 \mathrm{~mm}$. George et al. [9] studied the surface roughness and its prediction in cylindrical grinding process based on Taguchi's method of optimization. The material hardness, work piece speed, and depth of cut were selected as input parameters and surface roughness was selected as response factor. An L9 orthogonal array was used for designing the experiment. The experiments were conducted on En 24, EN 31, and EN 353 materials using a cylindrical grinding machine. Surface roughness was measured using Mitotoyo surf test SJ-400 roughness tester. The authors found that the surface roughness decreases as the material hardness was increased. When the work piece speed was increased from 60 to $120 \mathrm{rpm}$ the surface roughness decreased. The surface roughness was also decreased when the depth of cut was increased from 10 to $20 \mu \mathrm{m}$. The minimum surface roughness obtained was $0.47 \mu \mathrm{m}$ at hardness value of $64 \mathrm{HRC}$, at work piece speed of $120 \mathrm{rpm}$ and when depth of cut was $20 \mu \mathrm{m}$. Regression equation was formulated based on obtained results. Shih et al. [10] used vitreous bond CBN wheel for grinding Zirconium and M2 tool steel. The authors concluded that high speed grinding does not improve surface finish and roundness of ground parts. Nathan et al. [11] in their work concluded that the 'time to burn' was a useful wheel life parameter which is the time after which the burn occurred from start of grinding with dressed wheel during continuous grinding. Shaji et al. [12] conducted the experiments on EN 31 steel to conclude that in case of graphite as lubricant, the tangential force and surface roughness were lower and normal force was higher as compared to those in traditional grinding.

\section{Objectives of Present Investigation}

On the basis of the literature following objective have been decided for this study:

1. To work out optimum set of input parameters for minimum out of roundness by using ANOVA method.

2. To confirm the validity of optimum set of input parameters obtained by conducting confirmation experiments. 


\section{Experimentation}

In this study AISI 4140 steel is selected as the work piece material, which is a chromium-molybdenum high tensile strength steel. It offers a very good balance of strength, toughness and wear resistance. AISI 4140 steel is used in manufacturing of axles, conveyor parts, gears, spindles, shafts, studs, pinions, pump shafts, rams, ring gears etc. Figure 1 shows the pictorial view of specimen used for this experimentation.

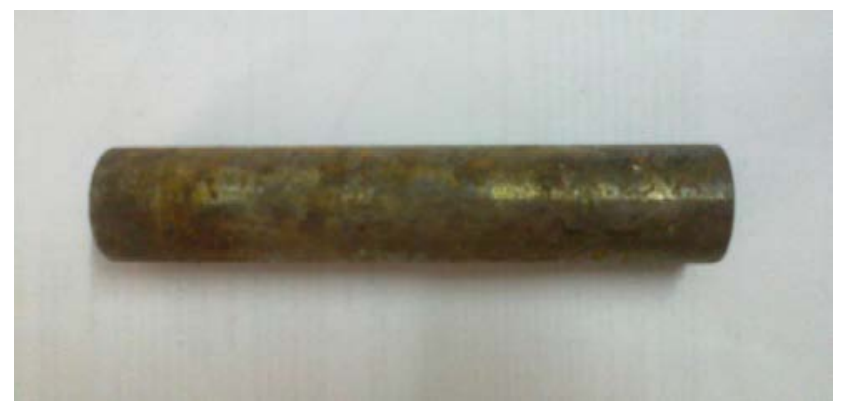

Figure 1. Specimen cut from raw material

Two factors i.e. surface roughness and out-of-roundness have been selected as response factors. The various parameters that influence these response factors are material of work piece, diameter of work piece, grain size of abrasive particles, grinding wheel speed, work piece speed, axial feed rate, depth of cut, coolant flow rate, concentration of cutting fluid, number of passes, etc. It has been found from the review of literature that the parameters like grinding wheel speed, work piece speed, grain size of abrasive particles, depth of cut, concentration of cutting fluid and number of passes are most critical and these have been selected as input parameters, in this study. For experimentation, two or three levels have been selected for each selected input parameter. The list of various input parameters along with their levels is given in Table 1. The L18 orthogonal array along with independent variables and their selected levels used for the experiment is shown in Table 2. The cylindrical grinding is performed on HMT G9 cylindrical grinding machine.

Table 1. Different input parameters and their levels

\begin{tabular}{|c|c|c|c|}
\hline \multirow{2}{*}{ Input Parameters } & & Levels & \\
\cline { 2 - 4 } & Level-1 & Level-2 & Level-3 \\
\hline Grinding wheel speed (rpm) & 2100 & 2640 & - \\
\hline Work piece speed (rpm) & 250 & 500 & 710 \\
\hline Grain size (mesh/inch) & 60 & 46 & 36 \\
\hline $\begin{array}{c}\text { Depth of cut ( } \mu \text { m) } \\
\text { Concentration of cutting fluid } \\
\text { (in \%) }\end{array}$ & 15 & 20 & 25 \\
\hline
\end{tabular}

Table 2. L18 experimental design for selected input parameters and their levels

\begin{tabular}{|c|c|c|c|c|c|c|}
\hline \multirow[b]{2}{*}{ Exp. No. } & A & B & $\mathrm{C}$ & $\mathrm{D}$ & $\mathrm{E}$ & $\mathrm{F}$ \\
\hline & $\begin{array}{l}\text { Wheel speed } \\
\text { (rpm) }\end{array}$ & $\begin{array}{l}\text { Work speed } \\
\text { (rpm) }\end{array}$ & $\begin{array}{c}\text { Grain size } \\
\text { (mesh/inch) }\end{array}$ & $\begin{array}{l}\text { Depth of cut } \\
(\mu \mathrm{m})\end{array}$ & $\begin{array}{l}\text { Concentration of cutting fluid } \\
\text { (in\%) }\end{array}$ & Number of passes \\
\hline 1 & 2100 & 250 & 60 & 15 & 3 & 2 \\
\hline 2 & 2100 & 250 & 46 & 20 & 4 & 3 \\
\hline 3 & 2100 & 250 & 36 & 25 & 5 & 4 \\
\hline 4 & 2100 & 500 & 60 & 15 & 4 & 3 \\
\hline 5 & 2100 & 500 & 46 & 20 & 5 & 4 \\
\hline 6 & 2100 & 500 & 36 & 25 & 3 & 2 \\
\hline 7 & 2100 & 710 & 60 & 20 & 3 & 4 \\
\hline 8 & 2100 & 710 & 46 & 25 & 4 & 2 \\
\hline 9 & 2100 & 710 & 36 & 15 & 5 & 3 \\
\hline 10 & 2640 & 250 & 60 & 25 & 5 & 3 \\
\hline 11 & 2640 & 250 & 46 & 15 & 3 & 4 \\
\hline 12 & 2640 & 250 & 36 & 20 & 4 & 2 \\
\hline 13 & 2640 & 500 & 60 & 20 & 5 & 2 \\
\hline 14 & 2640 & 500 & 46 & 25 & 3 & 3 \\
\hline 15 & 2640 & 500 & 36 & 15 & 4 & 4 \\
\hline 16 & 2640 & 710 & 60 & 25 & 4 & 4 \\
\hline 17 & 2640 & 710 & 46 & 15 & 5 & 2 \\
\hline 18 & 2640 & 710 & 36 & 20 & 3 & 3 \\
\hline
\end{tabular}

The results observed for out of roundness are shown in

\section{Results and Discussion}

\subsection{Results for Out-of-Roundness}

The results for all the experiments conducted according to Taguchi's orthogonal array are given in this section.
Table 3.

The minimum out-of-roundness obtained is $2 \mu \mathrm{m}$ at grinding wheel speed of $2100 \mathrm{rpm}$, work piece speed of $710 \mathrm{rpm}$, grain size of $36 \mathrm{mesh} / \mathrm{inch}$, depth of cut of 15 $\mu \mathrm{m}$, concentration of cutting fluid $5 \%$ and 3 number of passes. While worst out-of-roundness obtained is $19 \mu \mathrm{m}$ at wheel speed of $2100 \mathrm{rpm}$, work piece speed of $250 \mathrm{rpm}$, 
grain size of 46 mesh/inch, depth of cut of $20 \mu \mathrm{m}$, concentration of cutting fluid $4 \%$ and 3 number of passes.

Table 3. Results for out-of-roundness

\begin{tabular}{|c|c|c|c|c|c|c|c|}
\hline \multirow[b]{2}{*}{ Exp. No. } & $\mathrm{A}$ & B & $\mathrm{C}$ & $\mathrm{D}$ & $\mathrm{E}$ & $\mathrm{F}$ & \multirow{2}{*}{$\begin{array}{l}\text { Out-of- } \\
\text { roundness } \\
(\mu \mathrm{m})\end{array}$} \\
\hline & $\begin{array}{c}\text { Wheel speed } \\
\text { (rpm) }\end{array}$ & $\begin{array}{c}\text { Work speed } \\
\text { (rpm) }\end{array}$ & $\begin{array}{c}\text { Grain size } \\
\text { (mesh/inch) }\end{array}$ & $\begin{array}{l}\text { Depth of cut } \\
(\mu \mathrm{m})\end{array}$ & $\begin{array}{c}\text { Concentration of cutting fluid } \\
\text { (in \%) }\end{array}$ & Number of passes & \\
\hline 1 & 2100 & 250 & 60 & 15 & 3 & 2 & 17 \\
\hline 2 & 2100 & 250 & 46 & 20 & 4 & 3 & 19 \\
\hline 3 & 2100 & 250 & 36 & 25 & 5 & 4 & 13 \\
\hline 4 & 2100 & 500 & 60 & 15 & 4 & 3 & 4 \\
\hline 5 & 2100 & 500 & 46 & 20 & 5 & 4 & 9 \\
\hline 6 & 2100 & 500 & 36 & 25 & 3 & 2 & 5 \\
\hline 7 & 2100 & 710 & 60 & 20 & 3 & 4 & 6 \\
\hline 8 & 2100 & 710 & 46 & 25 & 4 & 2 & 12 \\
\hline 9 & 2100 & 710 & 36 & 15 & 5 & 3 & 2 \\
\hline 10 & 2640 & 250 & 60 & 25 & 5 & 3 & 4 \\
\hline 11 & 2640 & 250 & 46 & 15 & 3 & 4 & 17 \\
\hline 12 & 2640 & 250 & 36 & 20 & 4 & 2 & 7 \\
\hline 13 & 2640 & 500 & 60 & 20 & 5 & 2 & 10 \\
\hline 14 & 2640 & 500 & 46 & 25 & 3 & 3 & 9 \\
\hline 15 & 2640 & 500 & 36 & 15 & 4 & 4 & 15 \\
\hline 16 & 2640 & 710 & 60 & 25 & 4 & 4 & 8 \\
\hline 17 & 2640 & 710 & 46 & 15 & 5 & 2 & 15 \\
\hline 18 & 2640 & 710 & 36 & 20 & 3 & 3 & 5 \\
\hline
\end{tabular}

Table 4. S/N ratio for out-of-roundness

\begin{tabular}{|c|c|c|c|c|c|c|c|c|}
\hline \multirow[b]{3}{*}{ Exp. No. } & & & & & & & \multirow{3}{*}{$\begin{array}{l}\text { Out-of- } \\
\text { roundness } \\
(\mu \mathrm{m})\end{array}$} & \multirow{3}{*}{$\begin{array}{l}\mathrm{S} / \mathrm{N} \\
\text { ratio }\end{array}$} \\
\hline & A & B & C & D & E & $\mathrm{F}$ & & \\
\hline & $\begin{array}{c}\text { Wheel speed } \\
\text { (rpm) }\end{array}$ & $\begin{array}{c}\text { Work speed } \\
\text { (rpm) }\end{array}$ & $\begin{array}{l}\text { Grain size } \\
\text { (mesh/inch) }\end{array}$ & $\begin{array}{c}\text { Depth of cut } \\
(\mu \mathrm{m})\end{array}$ & $\begin{array}{l}\text { Concentration of cutting fluid } \\
\text { (in \%) }\end{array}$ & Number of passes & & \\
\hline 1 & 2100 & 250 & 60 & 15 & 3 & 2 & 17 & -24.60 \\
\hline 2 & 2100 & 250 & 46 & 20 & 4 & 3 & 19 & -25.57 \\
\hline 3 & 2100 & 250 & 36 & 25 & 5 & 4 & 13 & -22.27 \\
\hline 4 & 2100 & 500 & 60 & 15 & 4 & 3 & 4 & -12.04 \\
\hline 5 & 2100 & 500 & 46 & 20 & 5 & 4 & 9 & -19.08 \\
\hline 6 & 2100 & 500 & 36 & 25 & 3 & 2 & 5 & -13.98 \\
\hline 7 & 2100 & 710 & 60 & 20 & 3 & 4 & 6 & -15.56 \\
\hline 8 & 2100 & 710 & 46 & 25 & 4 & 2 & 12 & -21.58 \\
\hline 9 & 2100 & 710 & 36 & 15 & 5 & 3 & 2 & -6.02 \\
\hline 10 & 2640 & 250 & 60 & 25 & 5 & 3 & 4 & -12.04 \\
\hline 11 & 2640 & 250 & 46 & 15 & 3 & 4 & 17 & -24.60 \\
\hline 12 & 2640 & 250 & 36 & 20 & 4 & 2 & 7 & -16.90 \\
\hline 13 & 2640 & 500 & 60 & 20 & 5 & 2 & 10 & -20.00 \\
\hline 14 & 2640 & 500 & 46 & 25 & 3 & 3 & 9 & -19.08 \\
\hline 15 & 2640 & 500 & 36 & 15 & 4 & 4 & 15 & -23.52 \\
\hline 16 & 2640 & 710 & 60 & 25 & 4 & 4 & 8 & -18.06 \\
\hline 17 & 2640 & 710 & 46 & 15 & 5 & 2 & 15 & -23.52 \\
\hline 18 & 2640 & 710 & 36 & 20 & 3 & 3 & 5 & -13.98 \\
\hline
\end{tabular}

\subsection{S/N Ratios for Out-of-Roundness}

Out-of-roundness is the difference between minimum and maximum radius of the work-piece. The Table 4 consists of values of out-of-roundness or radial run out for the eighteen trials and the $\mathrm{S} / \mathrm{N}$ ratio of out-of-roundness is also given.

In this experimental work, out-of-roundness is based on principle of 'lower is better' which is logarithmic function based on mean square deviation (MSD), given by

$$
S / N_{L B}=-10 \log (M S D)=-10 \log \left[1 / r \sum_{(i=0)}^{r} y_{i}^{2}\right]
$$

MSD $=$ Mean square deviation

$y_{i}=$ Observed value of the response characteristic $\mathrm{r}=$ Number of repetitions

\subsection{Analysis of Variance for Out-of- Roundness}

Results obtained from the experiments were analyzed using analysis of variance or ANOVA method. ANOVA method was applied to signal to noise ratio. For ANOVA analysis sum of squares $\left(S S_{A}\right)$, sum of squares total $\left(S S_{T}\right)$, sum of squares error $\left(S S_{E}\right.$ ) degree of freedom (DOF), variance and F-ratio have been calculated using following equations:

i) Calculating sum of squares total $\left(S S_{T}\right)$ :

$$
S S_{T}=\sum_{i=1}^{n}\left(y_{i}-\bar{T}\right)^{2}
$$


Where

$\mathrm{n}$ = number of response observations

$\bar{T}=$ mean of all observations

$i=1$ to $n$

ii) Calculating sum of squares $\left(S S_{A}\right)$ :

$$
S S_{A}=\left[\sum_{i=1}^{K_{A}}\left(\frac{A_{i}^{2}}{n_{A i}}\right)\right]-\frac{T^{2}}{N}
$$

Where

$S S_{A}=$ Square deviation of factor $\mathrm{A}$

$A_{i}=$ Average of all observations under $A_{i}$ level

$\mathrm{T}=$ Sum of all observations

iii) Calculating sum of squares error $\left(S S_{E}\right)$ :

$$
S S_{E}=\sum_{j=1}^{K_{A}} \sum_{i=1}^{n_{A i}}\left(y_{i}-\bar{A}_{j}\right)
$$

Where

$\mathrm{i}=1$ to $\mathrm{n}$

$n_{A i}=$ Number of observations under $A_{i}$ level (iv) Calculating variance, $F$ - ratio and percentage contribution: Variance is the ratio between sum of squares and degree of freedom.

$$
\text { Variance }=\frac{S S_{A}}{D O F}
$$

While F- ratio is the ratio between variance of each parameter and variance of residual error. Percentage contribution is the percentage of contribution of input parameter in the response factor which is the ratio of square deviation of factor $\mathrm{A}$ and sum of squares total i.e.

$$
\text { Pcontribution }=\frac{S S_{A}}{S S_{T}} \times 10
$$

After calculating for $\mathrm{S} / \mathrm{N}$ ratios for all the experiments ANOVA is carried out for obtained $\mathrm{S} / \mathrm{N}$ ratios as shown in Table 5 . The purpose of analysis of variance is to investigate the parameters that significantly affect the quality

\begin{tabular}{|c|c|c|c|c|c|}
\hline Source & Sum of squares & Degree of freedom & Variance & F-ratio & Percentage Contribution \\
\hline Wheel speed & 7.04 & 1 & 7.04 & 0.290 & $1.43 \%$ \\
\hline Work-piece speed & 64.32 & 2 & 32.16 & 1.324 & $13.05 \%$ \\
\hline Grain size & 130.66 & 2 & 65.33 & 2.689 & $26.51 \%$ \\
\hline Depth of cut & 4.44 & 2 & 2.22 & 0.091 & $0.90 \%$ \\
\hline Concentration of Cutting fluid & 18.34 & 2 & 9.17 & 0.377 & $3.72 \%$ \\
\hline No. of passes & 122.3 & 2 & 61.15 & 2.517 & $24.81 \%$ \\
\hline Residual error & 145.77 & 6 & 24.29 & & $29.57 \%$ \\
\hline Total & 492.87 & 17 & & & $100 \%$ \\
\hline
\end{tabular}
characteristics. Further, the percentage contribution of various input parameters is also calculated and shown in Table 5.

Table 5. Analysis of variance for $\mathrm{S} / \mathrm{N}$ ratios of out-of-roundness

Table 6. Response table for mean $\mathrm{S} / \mathrm{N}$ ratios of out-of-roundness

\begin{tabular}{|c|c|c|c|c|c|c|}
\hline \multirow{2}{*}{ Level } & A & B & C & D & F \\
\cline { 2 - 6 } & Wheel speed & Work-piece speed & Grain size & Depth of cut & Concentration of cutting fluid & Number of passes \\
\hline $\mathbf{1 .}$ & $-17.85^{* *}$ & -21.00 & -17.05 & -19.05 & -18.63 \\
\hline $\mathbf{2 .}$ & -19.07 & -17.95 & -22.24 & -18.51 & -19.61 \\
\hline 3. & - & $-16.45^{* *}$ & $-16.11^{* *}$ & $-17.84^{* *}$ & $-17.93^{* *}$ \\
\hline Delta & 1.22 & 4.55 & 6.13 & 1.21 & $-14.79^{* *}$ & -20.51 \\
5.72 & 4 \\
\hline
\end{tabular}

Since $F_{0.05,1,6}=5.99$ and $F_{0.05,2,6}=5.14$, none of the effects are significant. The error variation of $29.57 \%$ is due to uncontrollable parameters and/or some parameters that would not have been included that may affect the outof-roundness. The percentage contribution indicates that the out-of-roundness is maximum affected by abrasive grain size followed by number of passes, work piece speed, concentration of cutting fluid, wheel speed. The depth of cut has least percentage contribution which is only $0.90 \%$.The effect of grinding wheel speed, concentration of cutting fluid and depth of cut is not much significant. The response table for $\mathrm{S} / \mathrm{N}$ ratios of out-of-roundness is represented in Table 6.

\subsection{Main Effect Plots for Out-of-Roundness}

The plot of $\mathrm{S} / \mathrm{N}$ ratio of out-of-roundness (OR) for grinding wheel speed is shown in Figure 2. The $\mathrm{S} / \mathrm{N}$ ratio is higher for grinding wheel speed of $2100 \mathrm{rpm}$ and it decreases when grinding wheel speed is changed from $2100 \mathrm{rpm}$ to $2640 \mathrm{rpm}$. Since higher the S/N ratio more favorable is the effect of parameter and hence $2100 \mathrm{rpm}$ is optimum value of grinding wheel speed for minimum out- of-roundness. The out-of-roundness increases at $2640 \mathrm{rpm}$, this may be due to possible increase in vibrations at high speeds.

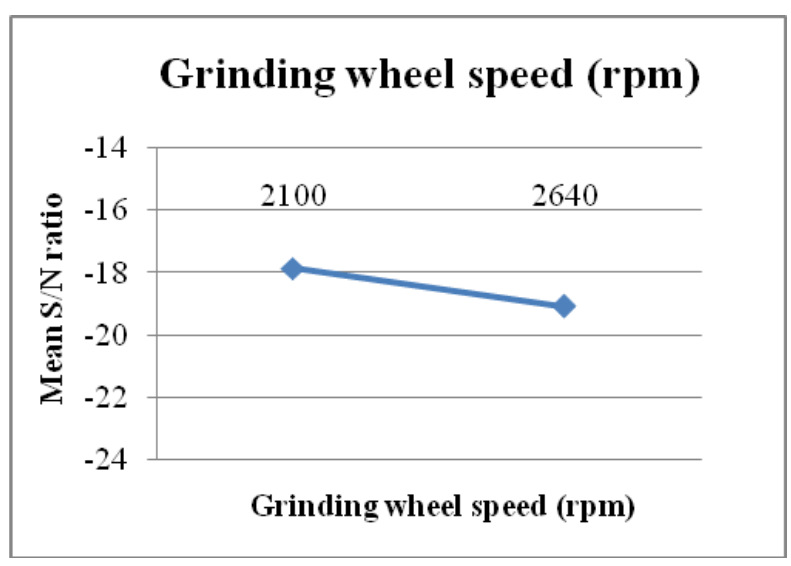

Figure 2. Main effect plot for means of $\mathrm{S} / \mathrm{N}$ ratios of OR for grinding wheel speed

In case of work piece speed, $\mathrm{S} / \mathrm{N}$ ratio increases as speed is increased from $250 \mathrm{rpm}$ to $500 \mathrm{rpm}$ and it further 
increases as speed is changed to $710 \mathrm{rpm}$, this shows that $\mathrm{S} / \mathrm{N}$ ratio is maximum for work piece speed of $710 \mathrm{rpm}$ and higher $\mathrm{S} / \mathrm{N}$ ratio means better roundness as shown in Figure 3.

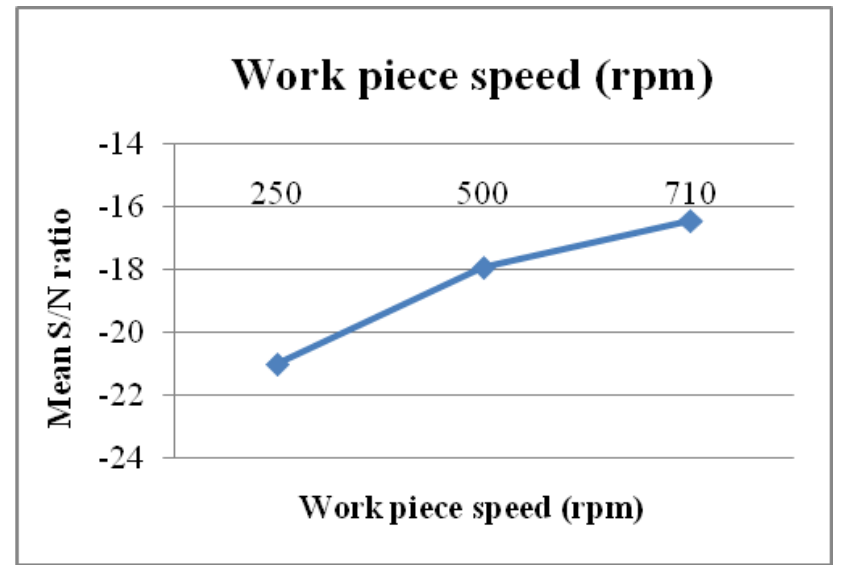

Figure 3. Main effect plot for means of $\mathrm{S} / \mathrm{N}$ ratios of OR for work piece speed

The $\mathrm{S} / \mathrm{N}$ ratio plot for grain size is given in Figure 4, the $\mathrm{S} / \mathrm{N}$ ratio is maximum at grain size of 36 mesh/inch which will give minimum out-of-roundness. Further, the change in $\mathrm{S} / \mathrm{N}$ ratio with change in grain size is large as compared to other parameters due to which grain size is most significant factor for out-of-roundness.

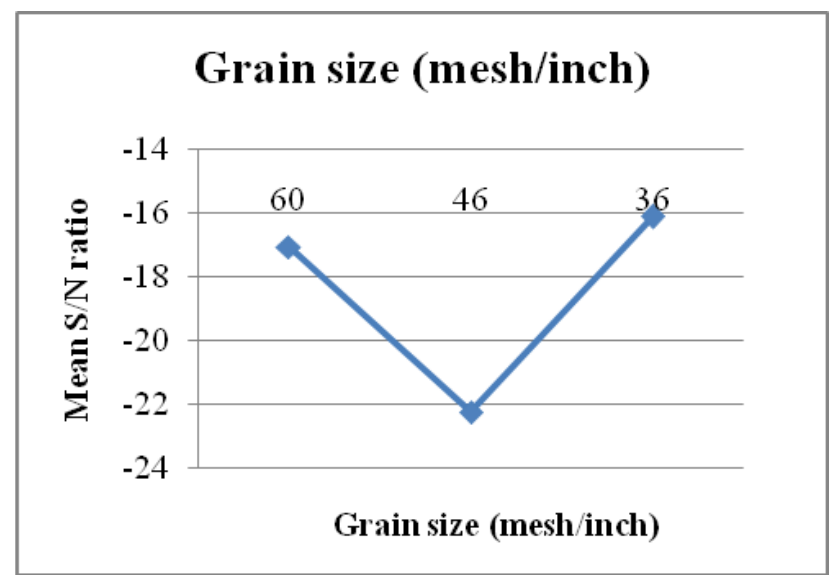

Figure 4. Main effect plot for means of $\mathrm{S} / \mathrm{N}$ ratios of OR for grain size

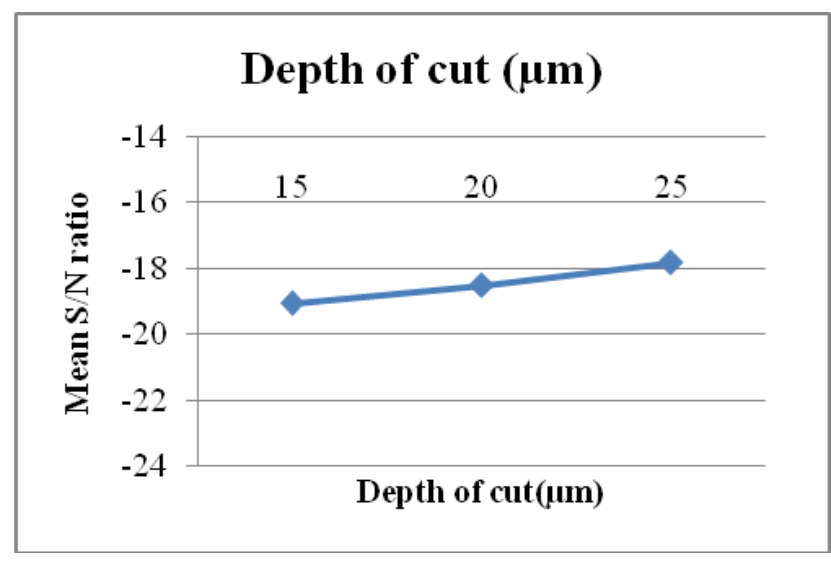

Figure 5. Main effect plot for means of S/N ratios of OR for depth of cut

The $\mathrm{S} / \mathrm{N}$ ratio increases as we increase depth of cut from $15 \mu \mathrm{m}$ to $20 \mu \mathrm{m}$ and from $20 \mu \mathrm{m}$ to $25 \mu \mathrm{m}$, the increase is gradual but small. The highest value of $\mathrm{S} / \mathrm{N}$ ratio is at depth of cut of $25 \mu \mathrm{m}$ which is optimum level for better roundness as shown in Figure 5.

For concentration of cutting fluid as shown in Figure 6, the $\mathrm{S} / \mathrm{N}$ ratio first decreases and then increases as concentration of cutting fluid is changed from 3\% to $4 \%$ and then from $4 \%$ to $5 \%$ with higher value at $5 \%$. Hence $5 \%$ concentration of cutting fluid is optimum level for minimum roundness error.

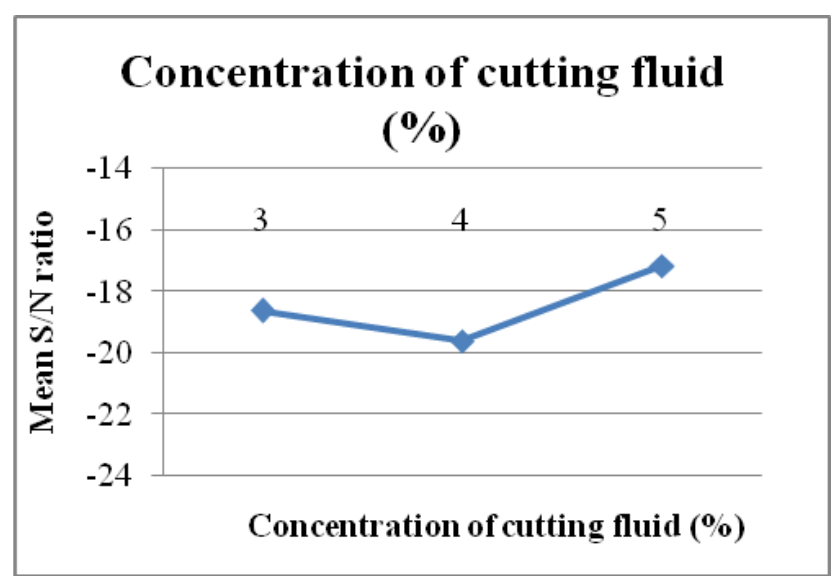

Figure 6. Main effect plot for means of $S / N$ ratios of $O R$ for concentration of cutting fluid

The $\mathrm{S} / \mathrm{N}$ ratio increases suddenly when number of passes were increased from 2 to 3, with highest value of $\mathrm{S} / \mathrm{N}$ ratio at 3 number of passes and it decreases when number of passes further increased to 4. Hence out-ofroundness decreases when number of passes is increased from 2 to 3 and it decreases when number of passes is further increased from 3 to 4 shown in Figure 7.

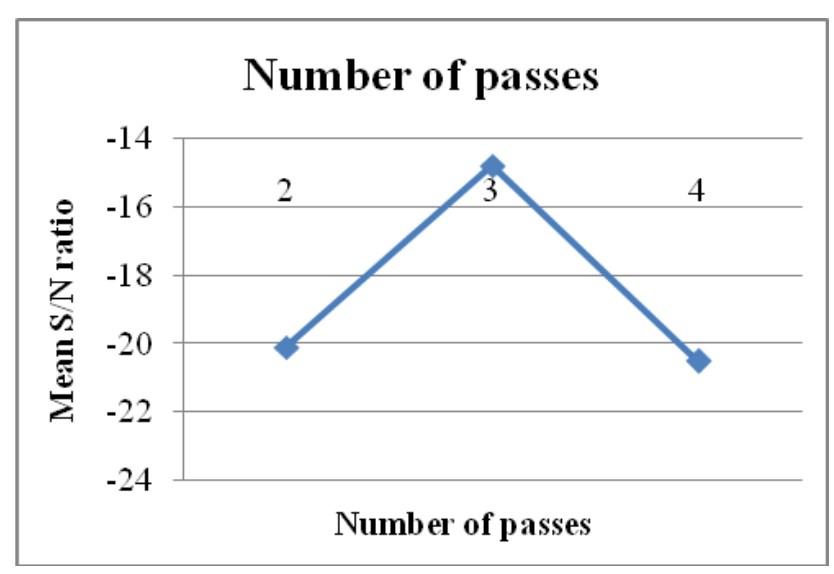

Figure 7. Main effect plot for means of S/N ratios of OR for number of passes

\subsection{Optimum Set of Parameters for Out-of- Roundness}

Table 7. Optimum set of parameters for minimum out-of-roundness

\begin{tabular}{|c|c|c|c|}
\hline Parameter & Units & $\begin{array}{c}\text { Optimum } \\
\text { level }\end{array}$ & $\begin{array}{c}\text { Optimum } \\
\text { value }\end{array}$ \\
\hline Wheel speed & $\mathrm{rpm}$ & $\mathrm{A} 1$ & 2100 \\
\hline Work-piece speed & $\mathrm{rpm}$ & $\mathrm{B} 3$ & 710 \\
\hline Grain size & Mesh/inch & $\mathrm{C} 2$ & 36 \\
\hline Depth of cut & $\mu \mathrm{m}$ & $\mathrm{D} 1$ & 25 \\
\hline $\begin{array}{c}\text { Concentration of } \\
\text { Cutting fluid }\end{array}$ & $\%$ & $\mathrm{E} 1$ & 5 \\
\hline No. of passes & - & $\mathrm{F} 1$ & 3 \\
\hline
\end{tabular}


From the response table i.e. Table 6 for $\mathrm{S} / \mathrm{N}$ ratios of out-of-roundness it is found that the optimum value of levels of input parameters for best out-of-roundness (minimum) are grinding wheel speed of 2100 rpm, workpiece speed $710 \mathrm{rpm}$, grain size 36 mesh/inch, depth of cut $25 \mu \mathrm{m}$, concentration of cutting fluid 5\% and number of passes 3. Table 7 gives the optimum levels of input parameters for minimum out-of-roundness.

\section{Confirmatory Experiments}

The confirmatory experiment is a crucial step and is highly recommended by Taguchi to verify the experimental results. The experimental confirmatory test is the final step in verifying the results drawn based on Taguchi's design approach. The optimal conditions are set for the significant parameters and a selected number of experiments are run under specified cutting conditions. In this study, two confirmatory experiments were conducted by using the optimal levels of the optimal process parameters for out-of-roughness.

\subsection{Predicting and Comparing the Optimum Response}

For predicting the optimum response approximately half of the total number of parameters are selected. Say $\bar{A}_{1}, \bar{B}_{1}, \bar{C}_{1}$ are means of response values for the optimum level of parameters having high percentage contribution. To find out predicted value of the response factor following equation is used:

$$
\mu \text { predicted }=\bar{Y}+\left(\bar{A}_{1}-\bar{Y}\right)+\left(\bar{B}_{1}-\bar{Y}\right)+\left(\bar{C}_{1}-\bar{Y}\right)
$$

where

$$
\bar{Y}=\frac{\text { Grand total of all observations }}{\text { Total number of observations }}
$$

For out-of-roundness predicted value $=2.65 \mu \mathrm{m}$

The confirmation test values of out-of-roundness obtained were $2 \mu \mathrm{m}$ and $3 \mu \mathrm{m}$. The values of out-ofroundness obtained are around the predicted value of 2.65 $\mu \mathrm{m}$.

\section{Conclusions}

In this experimental work, the results of six independent variables viz. grinding wheel speed, work piece speed, abrasive grain size, depth of cut, concentration of cutting fluid and number of passes have been studied for out-of-roundness error using ANOVA method. The important conclusions are as follows:

- It has been found that out of various input parameters abrasive grain size is the most significant parameter.

- The depth of cut is found to be least significant parameter.
- Abrasive grain size, number of passes and work piece speed has higher percentage contribution than depth of cut, grinding wheel speed and concentration of cutting fluid.

- Large decrease in out-of-roundness is observed when abrasive grain size was changed from 60 mesh/inch to 46 mesh/inch.

- There is sudden decrease in out-of-roundness when grain size was changed from 46 mesh/inch to 36 mesh/inch. Similarly large variation is observed when number of passes are changed from 2 to 3 and from 3 to 4.

- The optimum set of parameters for minimum out-ofroundness are; grinding wheel speed of 2100 rpm; work-piece speed at $710 \mathrm{rpm}$; grain size is 36 mesh/inch; depth of cut is $25 \mu \mathrm{m}$; concentration of cutting fluid is $5 \%$ and number of passes are equal to 3.

\section{References}

[1] Xue, L., Naghdy, F.,Cook, C.), "Monitoring of Wheel Dressing Operations for precision Grinding", FIEEE International Conference on Industrial Technology, 2,.1296-99, 2002.

[2] Chidambaram, S., Pei, Z.J., Kassir, S., "Fine Grinding of Silicone Wafers: a Mathematical Model for Grinding Marks", International Journal of Machine tools and Manufacture, 34(15), 1595-1602, 2003.

[3] Krajnik, P., Kopac, J., Saluga, A.,, "Design of Cylindrical Grinding Factors based on Response Surface Methodology", Journal of Material Processing Technology, 2, 629-36, 2005.

[4] Kwak, J.S., "Application of Taguchi and Response Surface Methodologies for Geometric Error in Surface grinding Process", International Journal of Machine Tools and Manufacture, 45, 327-34, 2005

[5] Marsh, E.R., Moerlein, A.W., Deakyne, T.R.S., Doren M.J.V., "In-process Measurement of Form Error and Force in CylindricalPlunge Grinding”, Precision Engineering, 32, 348-52, 2008.

[6] Agarwal, S., Rao, P.V., "Modeling and Prediction of Surface Roughness in Ceramic Grinding”, International Journal of Machine Tools and Manufacture, 50, 1065-76,2010

[7] Kadirgama, K., Rahman, M.M., Ismail, A.R., Bakar, R.A., "A Surrogate Modelling to Predict Surface Texture when Grinding AISI 1042 Carbon Steel”, Scientific Research and Essays, vol. 7(5), 598-608, 2012.

[8] Kumar, K., Chattopadhyaya, S., Singh, H., "Optimal Material Removal and Effect of Process Parameters of Cylindrical Grinding Machine by Taguchi Method”, International Journal of Advanced Engineering Research and Studies, 2(1), 39-43, 2012.

[9] George, L.P., Job, K.V., Chandran, I.M., "Study on Surface Roughness and its Prediction in Cylindrical Grinding Process based on Taguchi method of Optimization”, International Journal of Scientific and Research publications, 3(5), 2013.

[10] Shih, A.J., Grant, M.B., Yonushonis T.M., Morris, T.O., McSpadden, S.B., "Vitreous Bond CBN Wheel for High Speed Grinding of Zirconia and M2 Tool Steel", Transactions of NAMRI/SME, 26, 195-200, 1998.

[11] Nathan, R.D., Vijayaraghavan, L., Krishnamurthi, R., "In-process Monitoring of Grinding Burn in Cylindrical Grinding of Steel”, Journal of Material Processing Technology, 91, 37-42, 1999.

[12] Shaji, S., Radhakrishnan, V., "Analysis of Process Parameters in Surface Grinding with Graphite as Lubricant based on Taguchi Method”, Journal of Materials Processing Technology, 141, 51-59. 2003. 